\title{
Provided support, caregiver burden and well-being in partners of persons with spinal cord injury 5 years after discharge from first inpatient rehabilitation
}

\author{
Eline W. M. Scholten ${ }^{1} \cdot$ Anneroos Kieftenbelt $^{1} \cdot$ Chantal F. Hillebregt $^{1} \cdot$ Sonja de Groot $^{2,3} \cdot$ Marjolijn Ketelaar $^{1}$. \\ Johanna M. A. Visser-Meily ${ }^{1,4} \cdot$ Marcel W. M. Post ${ }^{1,5}$
}

Received: 20 September 2017 / Revised: 22 November 2017 / Accepted: 23 November 2017 / Published online: 16 January 2018

(c) International Spinal Cord Society 2018

\begin{abstract}
Study design Cross-sectional study.

Objectives To describe type and regularity of support given by partners for individuals with paraplegia versus tetraplegia 5 years after discharge from first inpatient rehabilitation; to describe perceived caregiver burden, mental health and life satisfaction among partners; and to analyse determinants of perceived burden and the partner's mental health and life satisfaction. Setting The Netherlands.

Methods Participants were partners of persons with spinal cord injury (SCI) 5 years after discharge from first inpatient rehabilitation $(N=67)$. Participants completed a self-report questionnaire. Provided support was assessed with an existing scale consisting of 25 activities for which partners could indicate how often they provide support to the patient. Caregiver burden was assessed with the Caregiver Strain Index. Mental health was measured with the Short-Form Health Survey 36 (mental health subscale), and life satisfaction was measured with the Life Satisfaction Questionnaire.

Results Five years after inpatient rehabilitation, partners provided support with a large variety of activities. How often and in which activities partners provided support was associated with lesion level. About $43 \%$ of the partners experienced high levels of caregiver burden. Provided support was related to perceived burden $\left(r_{\mathrm{S}}=0.58\right)$ and life satisfaction $\left(r_{\mathrm{S}}=-0.24\right)$, and burden was negatively related to mental health $\left(r_{\mathrm{S}}=-0.47\right)$ and life satisfaction $\left(r_{\mathrm{S}}=-0.67\right)$.

Conclusions High levels of perceived burden among partners and the associations between higher burden with lower wellbeing show the importance to prevent caregiver overload in partners of individuals with SCI. Monitoring burden during regular rehabilitation visits may help to early detect burden.
\end{abstract}

Marcel W. M. Post

m.post@dehoogstraat.nl

1 Center of Excellence for Rehabilitation Medicine, Brain Center Rudolf Magnus, University Medical Center Utrecht, University Utrecht and De Hoogstraat Rehabilitation, Utrecht, The Netherlands

2 Amsterdam Rehabilitation Research Center Reade, Amsterdam, The Netherlands

3 University of Groningen, University Medical Center Groningen, Center for Human Movement Sciences, Groningen, The Netherlands

4 Department of Rehabilitation, Physical Therapy Science \& Sports, Brain Center Rudolf Magnus, University Medical Center Utrecht, Utrecht, The Netherlands

5 University of Groningen, University Medical Center Groningen, Center for Rehabilitation, Department of Rehabilitation Medicine, Groningen, The Netherlands

\section{Introduction}

Acquiring a spinal cord injury (SCI) not only has a major impact on the people with SCI themselves [1], but also heavily affects the lives of their partners (often referred as spouses or significant others). They also have to adapt their pre-injury lifestyle and get a dual role as partner and caregiver, often without sufficient preparation [2,3].

Most partners provide extensive support to individuals with SCI on a daily basis and for a long period $[4,5]$. Type and regularity of the support depend on the level and severity of the injury [6], varying from support in activities of daily living (ADL) and other practical support, to more emotional support [5]. However, we only found one study describing the specific activities with which partners provide support [5].

Providing support may be stressful for partners and result in the experience of caregiver burden. Burden is a highly 
individualised experience [7]. It is often defined as the extent to which caregivers perceive that caregiving has had an adverse effect on their emotional, social, financial, physical or spiritual functioning [8]. Previous studies showed that about 40-46 percent of the partners experience moderate to serious levels of caregiver burden $[5,9,10]$. Increased hours of care, more moderate or severe disabilities of the patient, residence with the patient, lack of choice in being a caregiver, providing more ADL support and social isolation are related to higher perceived burden [5, 10-12]. Higher perceived burden has consequences for the caregiving partner in terms of lower general health [13], lower participation [9, 14], lower well-being, loss of identity or burnout $[2,15-17]$, but also for the individual with SCI, e.g., negative effect on the quality of their relationship [17] and society, e.g., financial consequences due to lostproductivity, absenteeism and burnout [18].

At this time, only little is known about the specific activities with which partners provide support, how often they provide support and how this relates to caregiver burden [5]. Furthermore, it is unclear how to prevent and reduce caregiver burden and its consequences on partners' well-being. Research in other diagnostic groups, suggest interventions such as counselling, psycho-education and family group interventions [19-21]. However, more research is needed to further develop and implement such interventions in SCI care [22, 23]. Therefore, more insight in the determinants of burden and well-being is needed [22]. The aims of the present study, therefore, were: (1) to describe the type of activities and regularity with which partners provide support to individuals with paraplegia and tetraplegia 5 years after discharge from first inpatient rehabilitation, (2) to describe perceived levels of caregiver burden, mental health and life satisfaction in partners of individuals with SCI and (3) to analyse determinants of perceived burden, mental health and life satisfaction.

\section{Methods}

\section{Design}

We used data from the Dutch Umbrella project [24]. In this study, individuals with SCI were included between August 2000 and July 2003, and they were followed during and after their first rehabilitation after onset of the lesion in one of the eight Dutch rehabilitation centres specialised in SCI [24].

\section{Participants}

Individuals with SCI were included in the project if they met the inclusion criteria: (1) age between 18 and 65 years, (2) recent onset of SCI and (3) expectation of permanent wheelchair dependency. Exclusion criteria were: (1) progressive disease, (2) psychological disorder, (3) SCI caused by a malignant tumour or (4) insufficient understanding of the Dutch language [24].

At the assessment 5 years after discharge, we also invited the primary family caregivers of the participants for the study. To get a more homogeneous group, we selected only partners (e.g., no children, parents or other primary family caregivers) who lived together with the individual with SCI at time of measurement. In the current study, we used data from couples of individuals with SCI and their partners.

\section{Procedure}

We asked individuals with SCI and their partners to complete a self-report questionnaire. Information on the type of SCI was extracted from data collected by a rehabilitation physician at 1 year post discharge. A research assistant administered the functional independence measure of individuals with SCI at time of assessment 5 years after discharge.

\section{Measures}

\section{Dependent variables}

Provided support by partners to individuals with SCI was measured with a scale developed in a previous study, consisting of 25 support activities [5]. Partners were asked: 'How often do you support your partner in the following activities?'. Answers were given on a 4-point scale (never to always). Items were grouped into three subscales: ADL support (preparing meals, various helping hands, transfers, dressing, outdoors transportation, moving around outdoors, bladder control, bowel control, eating/drinking, toileting, washing/showering, communication, grooming and moving around indoors), other practical support (visiting doctor, arranging for care or support, supplying medication, supplying ADL materials, arranging for supplies, arranging for adaptations, giving medication, putting on splints or orthoses and performing exercises), and emotional support (learning to live with the SCI, and comforting, enlivening). Average scores (range 1-4) were computed for each subscale and for the total scale. Cronbach's alphas were, respectively, $0.89,0.89,0.83$ and 0.94 in the present study.

We further asked individuals with SCI to report the average hours of support per week provided by the partner and by paid support providers.

Caregiver burden was assessed with the caregiver strain index (CSI), consisting of 13 dichotomous (yes or no) items [25]. We computed sum scores (range 0-13), where higher scores reflect higher levels of burden. Scores of $\geq 7$ indicate high levels of burden and need for further assessment [25]. 
The CSI has shown good psychometric properties and was previously used in SCI research [10]. Cronbach's alpha in the present study was 0.84 .

Mental health was assessed with the mental health subscale of the Short-Form Health Survey (SF-36) [26]. This scale is an often used screening tool for mental health problems [27]. Items are scored on a 6-point scale, summed and transformed to a 100-point scale. Higher scores reflect better mental health, scores of $\leq 60$ indicate low mental health [28]. This scale showed validity in an SCI population [29] and is formerly used by caregivers from individuals with SCI [30]. Cronbach's alpha in the present study was 0.86 .

Life satisfaction was assessed with the Life Satisfaction Questionnaire (LiSat-9) [31]. Items were scored on a 6point scale ranged from 'very dissatisfying' to 'very satisfying'. This scale consists of nine items: one about 'life as a whole' and eight about the domains 'self-care ability', 'leisure situation', 'vocational/daily occupation', 'financial situation', 'sexual life', 'partnership relation', 'family life' and 'contacts with friends/acquaintances'. We calculated average scale scores, where higher scores reflect higher life satisfaction. Scores of $<4.5$ were interpreted as 'low life satisfaction', scores of $\geq 4.5$ as 'high life satisfaction'. The LiSat-9 has shown to be a valid measure to assess life satisfaction in partners from individuals with stroke [16]. Cronbach's alpha in the present study was 0.82 .

\section{Independent partner variables}

Information was collected about age, gender (male $=0$, female $=1$ ) and the presence of children (none $=0$, at least $1=1$ ), for which a distinction was made in resident and non-resident children. In accordance with the definition of employment of the International Labour Organisation, participation in paid work was dichotomised in at least $1 \mathrm{~h}$ per week (1) or not at all (0) [32]. Experienced health was measured with a single item on general health from the SF36, and the responses were dichotomised into 'good': excellent, very good and good (1); or 'poor': fair and poor (0).

\section{Independent variables for individuals with $\mathrm{SCl}$}

Demographic information included age, gender, presence of children, participation in paid work and experienced health. Furthermore, individuals with SCI reported their gross monthly family income in Euros.

We used established guidelines to assess SCI characteristics [33]. Level of SCI was dichotomised as tetraplegia (0) or paraplegia (1) and completeness of the SCI was dichotomised as motor complete (0) or motor incomplete SCI (1). A research assistant administered the 13-item motor score of the Functional Independence Measure (FIM-Motor) to measure independence in mobility and self-care [34-36]. Answers were given on a 7-point scale ranging from 'total assistance' to 'complete independence'. Sum scores were computed (range 13-91). The higher the score, the higher the level of functional independence. Cronbach's alpha in the present study was 0.97 .

\section{Statistical analyses}

We used descriptive statics to describe study population, provided support, burden, mental health and life satisfaction, in the total group and in the subgroups of partners from individuals with paraplegia and tetraplegia. We assessed internal consistency of scales by calculating Cronbach's alpha (a score of $\geq 0.7$ is interpreted as good) [37]. Mainly non-parametric analyses were conducted due to the ordinal level of most measures, Mann-Whitney $U$-tests for differences among persons with paraplegia and tetraplegia and Spearman's rho correlations to detect which variables related to burden, mental health and life satisfaction. Linear regression analyses (Enter method) were conducted to analyse determinants of perceived burden, mental health and life satisfaction. All independent variables which were significantly correlated $(p<0.05)$ with the respective dependent variable in bivariate analyses were included in the regression model. In the correlation and regression analyses, only age and gender of the partners were taken into account, because of the high correlations between age and gender of partners and age and gender of individuals with SCI. We did not include completeness of the SCI as determinant because only those expected to remain wheelchair-dependent were included in the study. In the regression analysis, we used transformed scores of mental health (square root transformation) because of the skewness of the score distribution. We assumed an unidirectional association between burden and mental health and life satisfaction, therefore, burden was included as a predictor in the analyses with mental health and life satisfaction as outcomes, but mental health and life satisfaction were not included as predictors in the model with burden as outcome. To reduce the number of predictors in the regression analyses, we only included total provided support. Data were analysed with IBM SPSS Statistics 24. A significance level of $p<0.05$ (two-tailed) was used. We used Cohen's standards to evaluate the correlation coefficients $(r=0.10-0.29$ weak, $r=0.30-0.49$ moderat, and $r \geq 0.50$ strong) [38].

\section{Statements of ethics}

We followed all applicable institutional and governmental regulations concerning the ethical use of human volunteers 
during the course of this research. The Medical Ethics Committee of the University Medical Centre Utrecht approved the study protocol. At inclusion in the cohort, individuals with SCI signed informed consent. Partners signed informed consent at their entry in the study.

\section{Results}

\section{Participants}

One-hundred forty-six of the 225 individuals with SCI who participated at baseline, completed the follow-up measurement 5 years after discharge. Of them, 80 lived together with a partner. In total, 98 primary informal caregivers participated in the study, of who 69 were a cohabiting partner $(70.4 \%)$. Two partners were excluded because of missing scores on the dependent variables, resulting in a sample of 67 couples of individuals with SCI and their partners. Table 1 displays demographic and injury characteristics.

Table 1 Background characteristics

\begin{tabular}{|c|c|c|c|c|}
\hline Characteristic & Partners & $N$ & $\begin{array}{l}\text { Individuals with } \\
\text { SCI }\end{array}$ & $N$ \\
\hline $\begin{array}{l}\text { Age in years (Mdn; } \\
\text { IQR) }\end{array}$ & $47.0(35.0-59.5)$ & 65 & $50.0(36.0-59.0)$ & 66 \\
\hline Gender (female) & $64.2 \%$ & 67 & $31.8 \%$ & 66 \\
\hline Paid work (yes) & $75.8 \%$ & 67 & $36.9 \%$ & 65 \\
\hline $\begin{array}{l}\text { Gross monthly family } \\
\text { income (Euro) }\end{array}$ & - & - & - & 59 \\
\hline$<1000$ & - & - & $5.1 \%$ & \\
\hline 1000-1999 & - & - & $13.6 \%$ & \\
\hline 2000-2999 & - & - & $22.0 \%$ & \\
\hline 3000-3999 & - & - & $30.5 \%$ & \\
\hline 4000-4999 & - & - & $5.1 \%$ & \\
\hline$\geq 5000$ & - & - & $23.7 \%$ & \\
\hline Children (at least 1) & $78.5 \%$ & 65 & $78.5 \%$ & 65 \\
\hline $\begin{array}{l}\text { Resident child } \\
\text { (at least } 1 \text { ) }\end{array}$ & $46.7 \%$ & 65 & $46.7 \%$ & 65 \\
\hline $\begin{array}{l}\text { Non-resident child } \\
\text { (at least 1) }\end{array}$ & $37.3 \%$ & 65 & $37.3 \%$ & 65 \\
\hline $\begin{array}{l}\text { Experienced health } \\
\text { (good) }\end{array}$ & $89.2 \%$ & 65 & $80.3 \%$ & 66 \\
\hline $\begin{array}{l}\text { Level of SCI } \\
\text { (paraplegia) }\end{array}$ & - & - & $73.1 \%$ & 67 \\
\hline $\begin{array}{l}\text { Completeness of SCI } \\
\text { (Motor complete) }\end{array}$ & - & - & $77.6 \%$ & 67 \\
\hline $\begin{array}{l}\text { FIM-Motor score (Mdn; } \\
\text { IQR) }\end{array}$ & - & - & $73.0(42.0-78.0)$ & 62 \\
\hline
\end{tabular}

$M d n$ median, IQR interquartile range, FIM Functional Independence Measure

\section{Support}

Figures 1-3 graph the percent frequency distribution of providing support 'often' to 'always' by type of support listed from frequent to infrequent. Overall, partners provided support in all three support categories often. Partners of individuals with tetraplegia provided more often support with total support, ADL support and other practical support, compared to partners of individuals with paraplegia. Only the regularity of provided emotional support did not differ significantly between the two groups (Table 2).

The number of hours of support by the partner and paid support showed a large variation. Individuals with tetraplegia received significantly more hours of support provided by their partners (median 13) as well as paid support (median 15), than individuals with paraplegia (median 0 and 0 , respectively). Higher number of hours of support provided by partners was moderately related with more hours of paid support $\left(r_{\mathrm{s}}=0.48, p<0.001\right)$.

\section{Burden, mental health and life satisfaction}

Partners had a median burden score of 6.0 (Table 2). We found no differences in perceived burden levels between partners of individuals with a paraplegia or tetraplegia. Overall, $43.3 \%$ of the partners had a burden score of $\geq 7.0$, $38.8 \%$ in the paraplegia and $55.6 \%$ in the tetraplegia subgroup.

Table 2 shows mental health and life satisfaction scores. We found no significant differences between the paraplegia and tetraplegia subgroups. It was found that $25.4 \%$ of the partners reported low mental health and $47.8 \%$ low life satisfaction.

\section{Relationships burden, mental health and life satisfaction}

Table 3 shows the correlations between burden, mental health, life satisfaction and other partner and SCI-related independent variables. The first rows show the associations between the dependent variables. Higher perceived burden was related to lower mental health and life satisfaction. Mental health and life satisfaction were positively related.

We found significant moderate to strong associations between higher burden and more often provided support (total, and all three subscales), more partner support hours, higher partners' age, lower experienced health of the individual with SCI and a lower FIM-Motor score. Better mental health showed a moderate association with better partners' experienced health and higher gross monthly family income. Higher life satisfaction was weakly to moderately associated with more total and ADL support, 


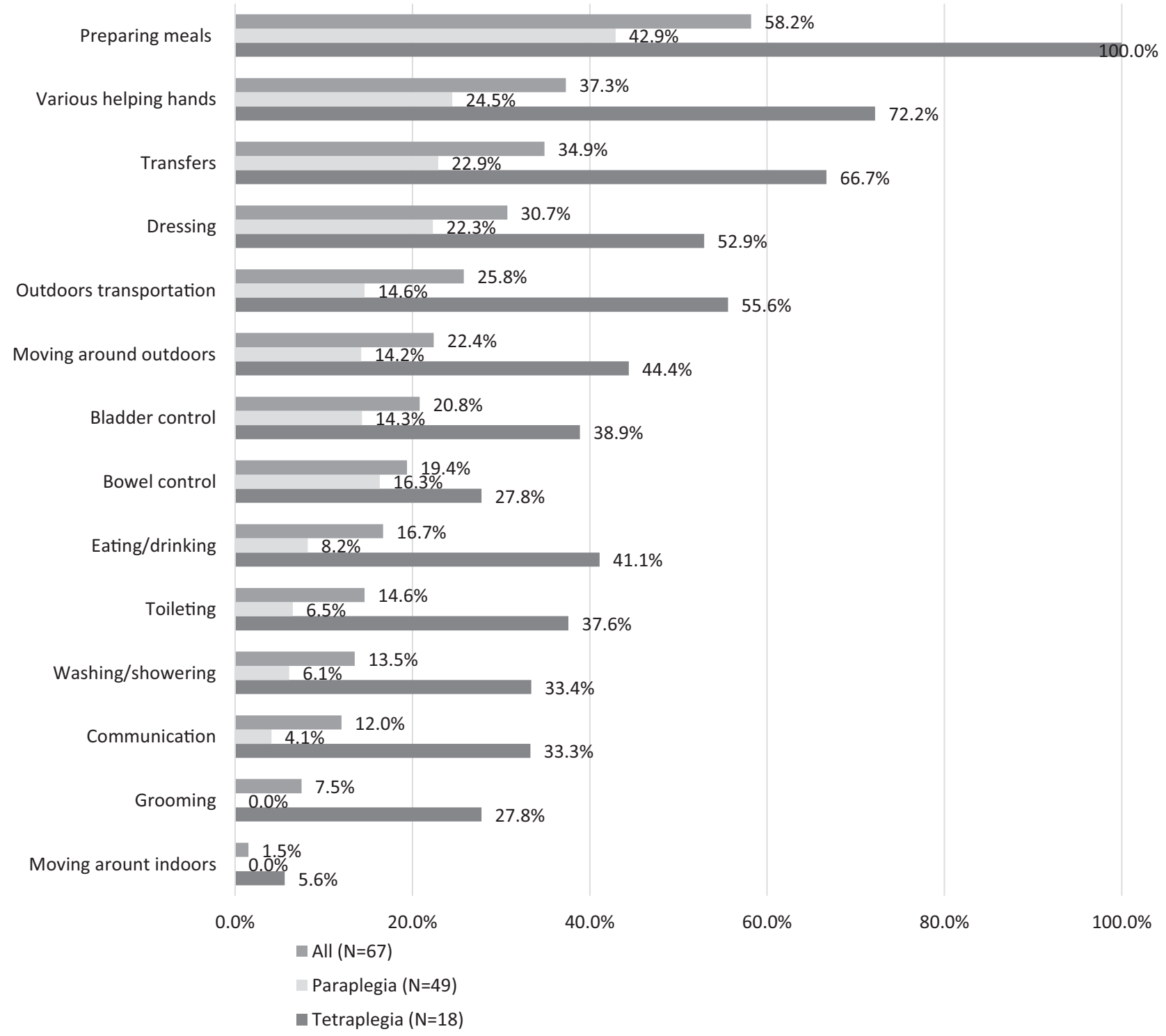

Fig. 1 The percent frequency distribution of providing ADL support 'often' to 'always' by type of support are listed from frequent to infrequent

lower partners' age and better experienced health of the individual with SCI.

Table 4 displays regression models. The strongest and only significant determinant of higher burden was more total provided support by the partner. The model explained $43.2 \%\left(R^{2}\right)$ of the variance in burden $(F(6)=6.6, p<$ $0.001)$. Lower burden, higher partners' experienced health and higher gross monthly family income were significant determinants of mental health and together they explained $40.9 \%\left(R^{2}\right)$ of the variance in mental health $(F(3)=12.2$, $p<0.001)$. The strongest determinant of higher life satisfaction was lower burden, followed by a higher amount of total provided support by the partner. The regression model explained $52.4 \%\left(R^{2}\right)$ of the variance in life satisfaction $(F(4)=16.5, p<0.001)$.

\section{Discussion}

In our study, we found that, 5 years after clinical discharge, above $40 \%$ of the partners from individuals with SCI perceived high levels of burden, that they often provide support in various different tasks, and that providing support and perceiving burden were strongly related. Higher burden also showed strong associations with worse mental health and life satisfaction.

Strengths of the study are the detailed description of partners support tasks and the focus on the consequences of an SCI on the lives of partners from individuals with SCI. Furthermore, as far as we know this is the first study in which the relationships between provided support, experienced burden and mental health and life satisfaction are investigated. 


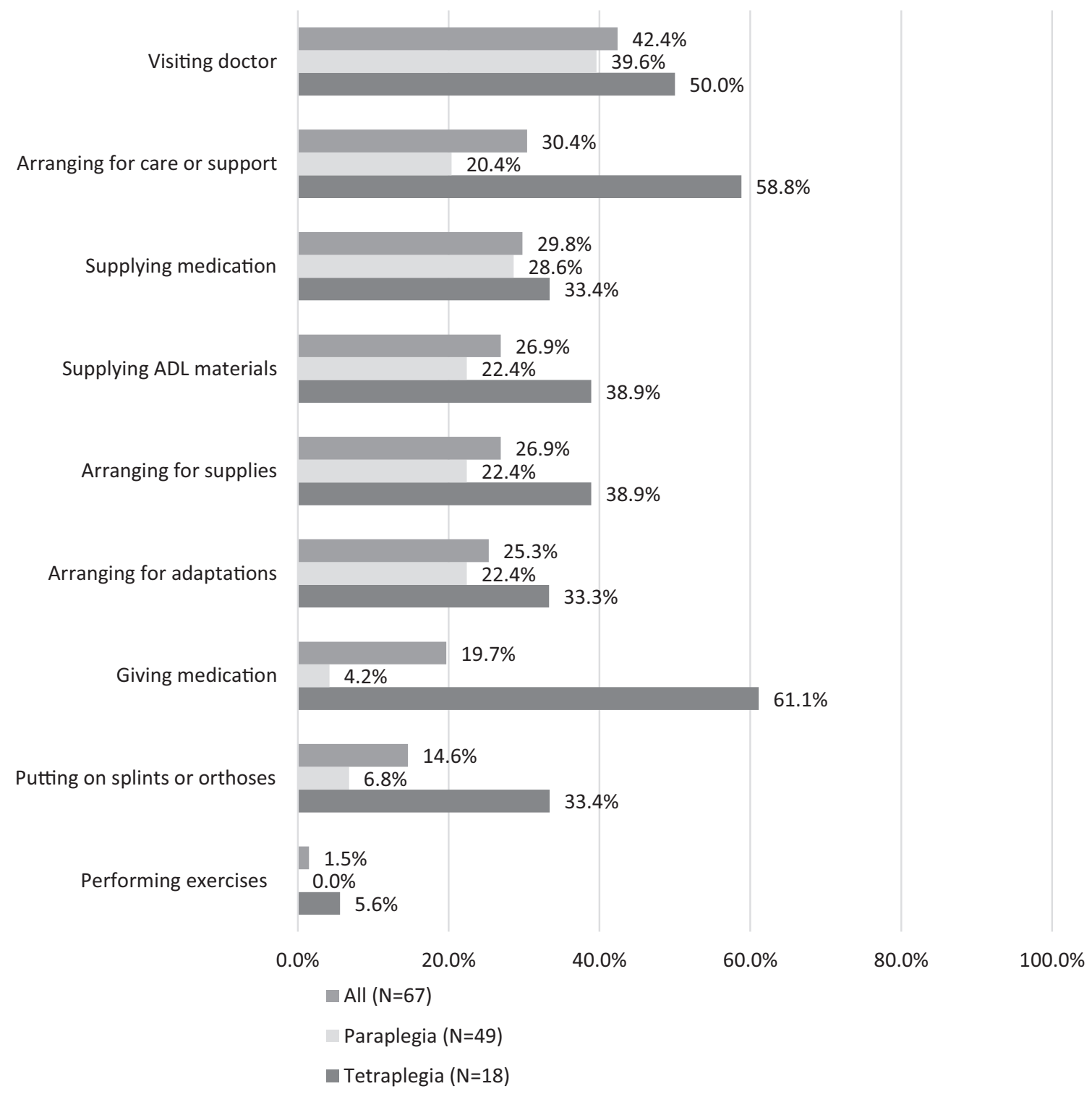

Fig. 2 The percent frequency distribution of providing other practical support 'often' to 'always' by type of support are listed from frequent to infrequent

Fig. 3 The percent frequency distribution of providing emotional support 'often' to 'always' by type of support are listed from frequent to infrequent

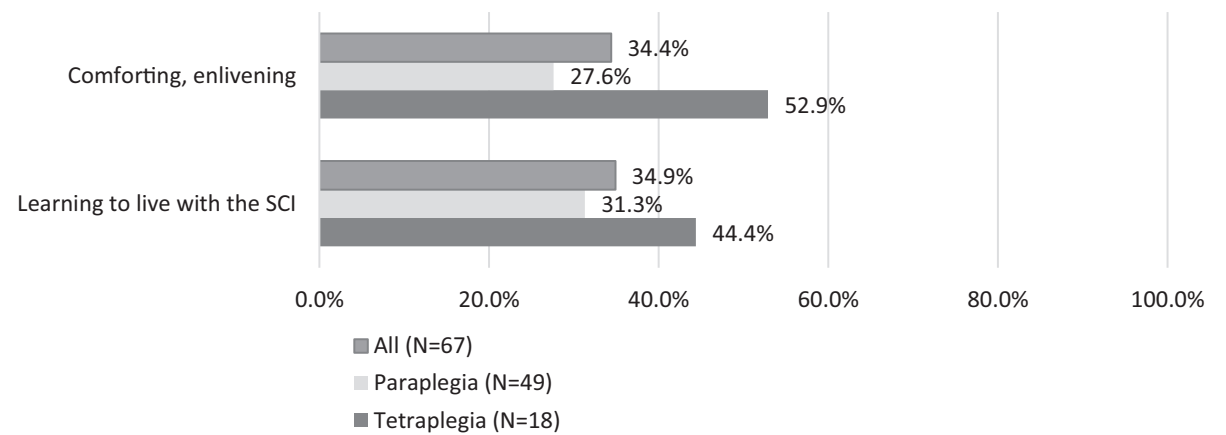




\section{Support}

That partners provide much support to individuals with SCI 5 years after discharge, confirms earlier research findings $[4,6,39]$. Compared to partners of individuals with paraplegia, partners of individuals with tetraplegia provide significantly more frequently support and more hours of support. Levels of support found in this study are similar to the results found in a study among partners on average 13 years after SCI [5]. This indicates that levels of
Table 2 Burden, support, hours of support, mental health and life satisfaction

\begin{tabular}{llllll}
\hline & All $(N=67)$ & $\begin{array}{l}\text { Paraplegia } \\
(N=49)\end{array}$ & $\begin{array}{l}\text { Tetraplegia } \\
(N=18)\end{array}$ & $z$ & $p$ \\
\hline $\begin{array}{l}\text { Burden }(0-12)^{\mathrm{a}} \\
\text { Support }\end{array}$ & $6.0(3.0-8.0)$ & $5.0(2.0-7.5)$ & $7.0(5.0-9.3)$ & 1.86 & 0.063 \\
$\quad$ Total support (1-4) & $1.8(1.4-2.3)$ & $1.6(1.3-2.0)$ & $2.3(1.9-2.7)$ & -3.72 & $<0.001$ \\
$\quad$ ADL support (1-4) & $1.7(1.4-2.2)$ & $1.5(1.3-1.9)$ & $2.3(2.1-2.7)$ & -4.52 & $<0.001$ \\
$\quad$ Other practical support & $1.6(1.3-2.3)$ & $1.4(1.2-2.0)$ & $2.0(1.6-2.9)$ & -2.57 & 0.010 \\
$\quad(1-4)$ & & & & & \\
$\quad$ Emotional support (1-4) & $2.0(1.9-3.0)$ & $2.0(1.5-3.0)$ & $2.5(2.0-3.1)$ & -1.78 & 0.075 \\
Hours of support (per week) & & & & & \\
$\quad$ By partner & $2.0(0.0-12.25)$ & $0.0(0.0-7.3)$ & $13.0(1.0-21.0)$ & -2.72 & 0.007 \\
$\quad$ Paid support & $2.3(0.0-9.3)$ & $0.0(0.0-5.3)$ & $15.0(4.0-35.5)$ & -3.82 & $<0.001$ \\
Mental health (0-100) & $76.0(60.0-88.0)$ & $76.0(62.0-88.0)$ & $78.0(60.0-85.0)$ & 0.02 & 0.983 \\
Life satisfaction $(1-6)^{\mathrm{b}}$ & $4.6(4.0-5.1)$ & $4.6(4.0-5.2)$ & $4.6(4.0-4.9)$ & 0.33 & 0.75 \\
\hline
\end{tabular}

Note: values are medians and interquartile range

${ }^{a}$ A higher score indicates more burden

${ }^{\mathrm{b}}$ A higher score indicates higher mental health/life satisfaction

Table 3 Spearman's rho correlations $(N=60-69)$

\begin{tabular}{|c|c|c|c|c|c|c|}
\hline & \multicolumn{2}{|l|}{ Burden } & \multicolumn{2}{|c|}{ Mental health } & \multicolumn{2}{|c|}{ Life satisfaction } \\
\hline & $r_{\mathrm{s}}$ & $p$ & $r_{\mathrm{s}}$ & $p$ & $r_{\mathrm{s}}$ & $p$ \\
\hline Mental health & -0.47 & $<0.001$ & - & - & - & - \\
\hline Life satisfaction & -0.67 & $<0.001$ & 0.73 & $<0.001$ & - & - \\
\hline Provided support by partner (total) & 0.58 & $<0.001$ & -0.20 & 0.104 & -0.24 & 0.048 \\
\hline ADL support & 0.59 & $<0.001$ & -0.17 & 0.163 & -0.25 & 0.042 \\
\hline Other practical support & 0.50 & $<0.001$ & -0.23 & 0.061 & -0.24 & 0.055 \\
\hline Emotional support & 0.42 & $<0.001$ & -0.09 & 0.446 & -0.09 & 0.460 \\
\hline \multicolumn{7}{|l|}{ Hours of support (per week) } \\
\hline By partner & 0.41 & 0.001 & -0.02 & 0.867 & -0.14 & 0.268 \\
\hline Paid support & 0.24 & 0.054 & -0.13 & 0.306 & -0.08 & 0.548 \\
\hline \multicolumn{7}{|l|}{ Partner variables } \\
\hline Age & 0.35 & 0.005 & -0.16 & 0.217 & -0.35 & 0.004 \\
\hline Gender (female) & -0.02 & 0.902 & -0.11 & 0.369 & -0.00 & 0.995 \\
\hline Paid work (yes) & -0.05 & 0.705 & 0.10 & 0.430 & 0.11 & 0.397 \\
\hline Children (total) & 0.34 & 0.007 & 0.00 & 0.990 & -0.18 & 0.180 \\
\hline Experienced health (good) & -0.14 & 0.277 & 0.28 & 0.023 & 0.24 & 0.057 \\
\hline \multicolumn{7}{|l|}{ Characteristics individuals with SCI } \\
\hline $\begin{array}{l}\text { Gross monthly family income } \\
\text { (Euro) }\end{array}$ & 0.14 & 0.298 & 0.28 & 0.034 & 0.21 & 0.120 \\
\hline $\begin{array}{l}\text { Experienced health patient } \\
\text { (good) }\end{array}$ & -0.24 & 0.049 & 0.13 & 0.304 & 0.30 & 0.013 \\
\hline FIM-Motor & -0.36 & 0.003 & 0.19 & 0.132 & 0.19 & 0.123 \\
\hline Lesion level (paraplegia) & -0.23 & 0.066 & 0.03 & 0.813 & 0.02 & 0.880 \\
\hline
\end{tabular}


Table 4 Linear regression analyses to detect variables associated with burden mental health and life satisfaction $(N=65)$

\begin{tabular}{lllll}
\hline & Beta & $t$-value & $p$-value & $\begin{array}{l}\text { Explained } \\
\text { variance }\left(R^{2}\right)\end{array}$ \\
\hline Dependent variable: burden & & & & $43.2 \%$ \\
$\quad$ Provided support by partner (total) & 0.54 & 3.23 & 0.002 & \\
Hours of support provided by partner & 0.09 & 0.59 & 0.560 & \\
Partner age & 0.06 & 0.46 & 0.646 & \\
Children (total) & 0.16 & 1.29 & 0.203 & \\
Experienced health patient (good) & -0.06 & -0.51 & 0.612 & \\
FIM-Motor & 0.05 & 0.36 & 0.723 & \\
Dependent variable: mental health (square root transformed) & & & & $40.9 \%$ \\
Burden & -0.50 & -4.48 & 0.001 & \\
Experienced health partner (good) & 0.24 & 2.20 & 0.032 & \\
Gross monthly family income (Euro) & 0.25 & 2.29 & 0.026 & \\
Dependent variable: life satisfaction & & & & $52.4 \%$ \\
Burden & -0.76 & -6.63 & 0.001 & \\
Provided support by partner (total) & 0.27 & 2.46 & 0.017 & \\
Partner age & -0.11 & -1.14 & 0.259 & \\
Experienced health patient (good) & 0.13 & 1.38 & 0.172 & \\
\hline
\end{tabular}

support provided by partners of individuals with SCI remain high on the long-term [40].

In our study, we also found a strong association between partner and paid support, which is consistent with previous research findings in which it was also found that paid care was received in addition to care given by family or friends $[5,6,41]$. This association indicates that support given by partners is not a substitute for professional care, but that it is supplemental.

Further, it is noticeable that the range of provided support is large, particularly in individuals with tetraplegia, with 1-21 $\mathrm{h}$ a week for partner support and 4-35.5 h a week for paid support. Large variance in this subgroup is not surprising, due to the large difference in level of functional independence. In our study, no information was collected on the time distribution of given support, so further research is needed in order to get more insight in how much time partners and/or professionals spend on specific different tasks.

\section{Burden}

In the present study, $43.3 \%$ of the partners showed serious levels of burden [25]. This percentage is comparable to the $46 \%$ Middleton et al. [10] found among caregivers of patients with SCI 2 years post discharge, which may indicate that burden is not a temporarily experienced feeling. Comparable percentages of 43-46\% were also found among partners of stroke patients 2 to 3 years post stroke [42, 43]. However, even higher levels of burden (51-80\%) were found in studies among caregivers of patients with amyotrophic lateral sclerosis [44] or dementia [45].
Only a trend towards significance $(p=0.06)$ was found for the differences in the levels of perceived burden between partners of individuals with paraplegia and tetraplegia. In previous research, a comparable but significant, difference in perceived caregiver burden was found among partners of persons with minor (mean $=1.6$, range $1-4$ ) and serious (mean $=2.3$ ) disabilities. The absence of significance in the current study is probably due to the low number of individuals with tetraplegia $(N=18)$.

\section{Mental health and life satisfaction}

While mental health and life satisfaction levels of partners from individuals with SCI were relatively low in previous research $[12,46]$, median mental health and life satisfaction scores in the present study were similar to the scores in the general Dutch population $[47,48]$. However, individual differences were large and $25.4 \%$ of the partners reported low mental health and $47.8 \%$ low life satisfaction, which are high proportions compared with the Dutch population $(13.7 \%$ and $34 \%$, respectively) $[49,50]$. Only part of the differences may be explained by gender differences, where females in the Dutch population report more often low mental health than males (respectively, $16.7 \%$ and $10.5 \%$ ) [49], and the majority of the partners in our study was female.

\section{Determinants of burden}

We found that higher burden was strongly and independently related to worse mental health and life satisfaction, which is consistent with earlier findings $[15,16,51]$. 
All three types of support were significantly related to burden, indicating that not only the more practical kinds of support like ADL (e.g., preparing meals and transfers) and other practical support (e.g., visiting a doctor and supplying medication), but also emotional support (comforting and learning to live with the SCI) relates with burden levels experienced by partners. We entered the total support variable in the regression analysis of burden, to restrict the number of independent variables and because all types of support were significantly related to burden. This variable turned out to be the only significant determinant of burden in the regression analysis with other variables, with a high explained variance $(43.2 \%)$, indicating the importance of total support provided by the caregiver in understanding perceived burden of the caregiver.

\section{Determinants of mental health and life satisfaction}

We found no significant differences in the experienced levels of mental health and life satisfaction between the paraplegia and the tetraplegia subgroups. This is unexpected, because we found strong correlations between total support and burden on the one hand, and between burden and mental health and life satisfaction on the other hand. While there were no or weaker correlations between support and mental health and life satisfaction, perceived burden seems to be the connecting factor.

More provided support by the partner was associated with lower life satisfaction in the bivariate analysis. Information about this association is not found in SCI research, but a study among caregiving elderly showed that providing daily care had a negative impact on caregiver's life satisfaction [52]. However, in the regression analysis provided support was positively related to life satisfaction, again suggesting that experienced burden rather than the amount of provided support is key to explain partner's mental health and life satisfaction.

Bivariate analyses showed that lower age and higher general health of the partner were related with higher life satisfaction, but these associations were not present in the regression analysis when burden was included as independent variable. Higher age and lower general health are both indicators of lower physical capacity, which may result in higher burden and thereby in lower life satisfaction.

In the regression analysis of mental health, besides burden, gross monthly family income and general health of the partner were related to mental health (positively, weak to moderate effect). In former research economic status is also found to be a determinant of mental health [53]. Mental health and general health are partly overlapping concepts [54], therefore, it is not surprising that these concepts are related.

\section{Limitations}

This study has some limitations. Firstly, the sample size; especially the tetraplegia group is small. Due to the limited sample size, we reduced the number of predictors in the regression analyses as much as possible. Secondly, this study concerned a group of selected partners of wheelchairdependent individuals with SCI. Therefore, our results were not representative for all partners of individuals with SCI. Thirdly, partners only participated in the study during the measurement 5 years after discharge, which makes it impossible to conclude anything about the course of providing support, perceived burden and well-being in the period between SCI onset and 5 years after discharge. However, in comparison with a former study, it appears that these results may be representative for a longer period [5]. Fourthly, no data were available about other determinants of burden, mental health and life satisfaction. Most consistent determinants of these constructs are patients behavioural problems, quality of the relationship between patient and partner [2], caregiver coping [19, 46], personality traits (resilience [55], neuroticism, self-efficacy), and caregiver competencies [21]. In future research, these determinants should be taken into account in order to get a more complete insight.

\section{Implications}

The high levels of burden among partners 5 years after discharge indicate that burden is not a temporarily experienced feeling. This emphasises the importance to regularly monitor burden among partners, in order to detect wellbeing problems. The CSI seems an useful tool which is easy to administer by a physician assistant during regular rehabilitation visits and quickly gives an indication of perceived burden [25, 43]. More attention from professionals is needed for partners who report high burden levels, and, therefore, are at risk for well-being problems.

The strong associations between burden with mental health and life satisfaction, as well as the consequences of caregiver burden on the individuals with SCI [17] and the society [18] found in former research, indicate the importance to prevent and treat caregiver burden. In order to reduce experiences of caregiver burden, it seems useful to develop interventions which help to reduce the levels of support provided by partners (e.g., relieving tasks). However, the weaker correlations between support and mental health and life satisfaction show that it may also be effective to relieve feelings of burden among partners even if the amount of support they provide does not change. Such interventions should focus on increasing partners ability to cope with caregiver burden (e.g., such as counselling, psycho-education and family group interventions). To 
relieve feelings of burden it seems important for future research to focus on individual characteristics, since in previous research it was found that personal characteristics like resilience [55], sense of control and coping style [46], influence how people deal with the situation they are in.

\section{Conclusion}

Partners often provide support in various tasks and perceive high levels of burden 5 years after discharge from inpatient rehabilitation. Burden was negatively related with mental health and life satisfaction in the predictive models including various independent partner and SCI characteristics, which indicates the potential negative consequences of burden on well-being and shows the importance to prevent caregiver overload in partners of individuals with SCI.

Funding The 5-year follow-up of the Umbrella project was funded by The Netherlands Organisation for Health Research and Development, grant number 14350003 .

\section{Compliance with ethical standards}

Conflict of interest The authors declare that they have no conflict of interest.

\section{References}

1 Post MWM, Van Leeuwen CMC. Psychosocial issues in spinal cord injury: A review. Spinal Cord. 2012;50:382-9.

2 Lynch J, Cahalan R. The impact of spinal cord injury on the quality of life of primary family caregivers: A literature review. Spinal Cord. 2017;55:964-78 (e-pub ahead of print).

3 Visser-Meily A, Post M, Gorter JW, Van Berlekom SB, Van Den Bos T, Lindeman E. Rehabilitation of stroke patients needs a family-centred approach. Disabil Rehabil. 2006;28:1557-61.

4 LaVela SL, Landers K, Etingen B, Karalius VP, Miskevics S. Factors related to caregiving for individuals with spinal cord injury compared to caregiving for individuals with other neurologic conditions. J Spinal Cord Med. 2015;38:505-14.

5 Post MWM, Bloemen J, de Witte LP. Burden of support for partners of persons with spinal cord injuries. Spinal Cord. 2005;43: 311-9.

6 Smith EM, Boucher E, Miller WC, SCIRE, Boucher N. Caregiving services in spinal cord injury: A systematic review of the literature. Spinal Cord. 2016;54:562-9.

7 Gillick MR. The critical role of caregivers in achieving patientcentered care. JAMA. 2013;310:575-6.

8 Zarit SH, Todd PA, Zarit JM. Subjective burden of husbands and wives as caregivers: A longitudinal study. Gerontologist. 1986;26: 260-6.

9 Rodakowski J, Skidmore ER, Rogers JC, Schulz R. Does social support impact depression in caregivers of adults ageing with spinal cord injuries? Clin Rehabil. 2013;27:565-75.

10 Middleton JW, Simpson GK, De Wolf A, Quirk R, Descallar J, Cameron ID. Psychological distress, quality of life, and burden in caregivers during community reintegration after spinal cord injury. Arch Phys Med Rehabil. 2014;95:1312-9.
11 Mitchell LA, Hirdes J, Poss JW, Slegers-Boyd C, Caldarelli H, Martin L. Informal caregivers of clients with neurological conditions: Profiles, patterns and risk factors for distress from a home care prevalence study. BMC Health Serv Res. 2015;15:350 (e-pub ahead of print).

12 Adelman RD, Tmanova LL, Delgado D, Dion S, Lachs MS. Caregiver burden: A clinical review. J Am Med Assoc. 2014;311: 1052-9.

13 Pinquart M, Sorensen S. Correlates of physical health of informal caregivers: A meta-analysis. J Gerontol. 2007;62:126-37.

14 Ellenbogen PS, Meade MA, Jackson MN, Barrett K. The impact of spinal cord injury on the employment of family caregivers. J Vocat Rehabil. 2006;25:35-44.

15 Rattanasuk D, Nantachaipan P, Sucamvang K, Moongtui W. A causal model of well-being among caregivers of people with spinal cord injury. Pac Rim Int J Nurs Res. 2013;17:342-55.

16 Kruithof WJ, Visser-Meily JMA, Post MWM. Positive caregiving experiences are associated with life satisfaction in spouses of stroke survivors. J Stroke Cerebrovasc Dis. 2012;21:801-7.

17 Tough H, Brinkhof MW, Siegrist J, Fekete C. Subjective caregiver burden and caregiver satisfaction: The role of partner relationship quality and reciprocity. Arch Phys Med Rehabil. 2017;98:2042-51 (e-pub ahead of print).

18 Ganapathy V, Graham GD, DiBonaventura MD, Gillard PJ, Goren A, Zorowitz R. Caregiver burden, productivity loss, and indirect costs associated with caring for patients with poststroke spasticity. Clin Interv Aging. 2015;10:1793-802 (e-pub ahead of print).

19 Huang M-F, Huang W-H, Su Y-C, Hou S-Y, Chen H-M, Yeh Y-C, et al. Coping strategy and caregiver burden among caregivers of patients with dementia. Am J Alzheimer's Dis Other Dement. 2015;30:694-8.

20 Visser-Meily A, Van Heugten C, Post M, Schepers V, Lindeman E. Intervention studies for caregivers of stroke survivors: A critical review. Patient Educ Couns. 2005;56:257-67.

21 Van der Lee J, Bakker TJEM, Duivenvoorden HJ, Dröes RM. Multivariate models of subjective caregiver burden in dementia: A systematic review. Ageing Res Rev. 2014;15:76-93.

22 Baker A, Barker S, Sampson A, Martin C. Caregiver outcomes and interventions: A systematic scoping review of the traumatic brain injury and spinal cord injury literature. Clin Rehabil. 2017;31(1): 45-60. https://doi.org/10.1177/0269215516639357.

23 Dyck DG, Weeks DL, Gross S, Lederhos Smith C, Lott HA, Wallace AJ et al. Comparison of two psycho-educational family group interventions for improving psycho-social outcomes in persons with spinal cord injury and their caregivers: A randomized-controlled trial of multi-family group intervention versus an active education control condition. BMC Psychol. 2016;4(1): 40. https://doi.org/10.1186/s40359-016-0145-0.

24 De Groot S, Dallmeijer A, Post M, Van Asbeck F, Nene A, Angenot E, et al. Demographics of the Dutch multicenter prospective cohort study 'Restoration of mobility in spinal cord injury rehabilitation'. Spinal Cord. 2006;44:668-75.

25 Robinson BC. Validation of a Caregiver Strain Index. J Gerontol. 1983;38:344-8.

26 Ware JE, Sherbourne CD. The MOS 36-Item Short-Form Health Survey (SF-36). Conceptual framework and item selection. Med Care. 1992;30:473-83.

$27 \mathrm{Ku} \mathrm{JH}$. Health-related quality of life in patients with spinal cord injury: Review of the short form 36-health questionnaire survey. Yonsei Med J. 2007;48:360-70.

28 Van Leeuwen CM, Hoekstra T, Van Koppenhagen CF, De Groot S, Post MW. Trajectories and predictors of the course of mental health after spinal cord injury. Arch Phys Med Rehabil. 2012;93: 2170-6. 
29 Van Leeuwen CMC, Van der Woude LHV, Post MWM. Validity of the mental health subscale of the SF-36 in persons with spinal cord injury. Spinal Cord. 2012;50:707-10.

30 Unalan H, Gençosmanoğlu B, Akgün K, Karamehmetoğlu S, Tuna $\mathrm{H}$, Ones K, et al. Quality of life of primary caregivers of spinal cord injury survivors living in the community: Controlled study with short form-36 questionnaire. Spinal Cord. 2001;39:318-22.

31 Fugl-Meyer AR, Branholm I-B, Fugl-Meyer KS. Happiness and domain-specific life satisfaction in adult northern Swedes. Clin Rehabil. 1991;5:25-33.

32 Statistics Netherlands (CBS). Statistics Netherlands opts for international definitions of unemployment and inflation. 2014. https://www.cbs.nl/en-gb/news/2014/27/statistics-netherlandsopts-for-international-definitions-of-unemployment-and-inflation (accessed 21 Jun 2017).

33 Maynard FM, Bracken MB, Creasey G, Ditunno JF, Donovan WH, Ducker TB, et al. International standards for neurological and functional classification of spinal cord injury. Spinal Cord. 1997:35:266-74.

34 Hall KM, Cohen ME, Wright J, Call M, Werner P. Characteristics of the Functional Independence Measure in traumatic spinal cord injury. Arch Phys Med Rehabil. 1999;80:1471-6.

35 Post MWM, Dallmeijer AJ, Angenot ELD, Van Asbeck FWA, Van der Woude LHVV. Duration and functional outcome of spinal cord injury rehabilitation in the Netherlands. J Rehabil Res Dev. 2005;42:75-85.

36 Kidd D, Stewart G, Baldry J, Johnson J, Rossiter D, Petruckevitch A, et al. The Functional Independence Measure: A comparative validity and reliability study. Disabil Rehabil. 1995;17:10-14.

37 Tavakol M, Dennick R. Making sense of Cronbach's alpha. Int J Med Educ. 2011;2:53-55.

38 Cohen J. Statistical power analysis for the behavioural sciences. 2nd ed. New York, NY: Academic Press; 1988.

39 Walker EA, Cao Y, Edles PA, Acuna J, Sligh-Conway C, Krause JS. Racial-ethnic variations in paid and unpaid caregiving: Findings among persons with traumatic spinal cord injury. Disabil Health J. 2015;8:527-34.

40 Liem NR, McColl MA, King W, Smith KM. Aging with a spinal cord injury: Factors associated with the need for more help with activities of daily living. Arch Phys Med Rehabil. 2004;85: 1567-77.

41 Kemp LA. Care and services for spinal injured people with, and without, neurological deficit. Disabil Rehabil. 2002;24:810-6.

42 Kruithof WJ, Post MWM, Van Mierlo ML, Van den Bos GAM, De Man-van Ginkel JM, Visser-Meily JMA. Caregiver burden and emotional problems in partners of stroke patients at two months and one year post-stroke: Determinants and prediction. Patient Educ Couns. 2016;99:1632-40.

43 Visser-Meily A, Post M, Van de Port I, Maas C, ForstbergWärleby G, Lindeman E. Psychosocial functioning of spouses of patients with stroke from initial inpatient rehabilitation to 3 years post stroke: Course and relations with coping strategies. Stroke. 2009;40:1399-404.

44 Galvin M, Corr B, Madden C, Mays I, McQuillan R, Timonen V, et al. Caregiving in ALS - A mixed methods approach to the study of Burden. BMC Palliat Care. 2016;15:81 (e-pub ahead of print).

45 Etters L, Goodall D, Harrison BE. Caregiver burden among dementia patient caregivers: A review of the literature. J Am Acad Nurse Pract. 2008;20:423-8.

46 Chan R. Stress and coping in spouses of persons with spinal cord injuries. Clin Rehabil. 2000;14:137-44.

47 Van Leeuwen CMC, Post MWM, Van Asbeck FWA, BongersJanssen HMH, Van der Woude LHV, De Groot S, et al. Life satisfaction in people with spinal cord injury during the first five years after discharge from inpatient rehabilitation. Disabil Rehabil. 2012;34:76-83.

48 De Vroome T, Hooghe M. Life satisfaction among ethnic minorities in the Netherlands: Immigration experience or adverse living conditions? J Happiness Stud. 2014;15:1389-406.

49 Driessen M. Geestelijke ongezondheid in Nederland in kaart gebracht [Mental health in the Netherlands]. The Hague (the Netherlands), 2011. http://www.cbs.nl/NR/rdonlyres/EF66D80A-C019-4EF0-8D134A54999C37EE/0/2011geestelijkeongezondheidinNederlandinkaa rtgebrachtart.pdf.

50 Post MWM, Van Dijk AJ, Van Asbeck FWA, Schrijvers AJP, Van Dijk AJ, Van Asbeck FWA, et al. Life satisfaction of persons with spinal cord injury compared to a population group. Scand J Rehabil Med. 1998;30:23-30.

51 Chappell NL, Reid RC. Burden and well-being among caregivers: Examining the distinction. Gerontologist. 2002;42:772-80.

52 Borg C, Hallberg IR. Life satisfaction among informal caregivers in comparison with non-caregivers. Scand J Caring Sci. 2006;20:427-38.

53 Meyer OL, Castro-Schilo L, Aguilar-Gaxiola S. Determinants of mental health and self-rated health: A model of socioeconomic status, neighborhood safety, and physical activity. Am J Public Health. 2014;104:1734-41.

54 Post MWM, De Witte LP, Schrijvers AJ. Quality of life and the ICIDH: Towards an integrated conceptual model for rehabilitation outcomes research. Clin Rehabil. 1999;13:5-15.

55 Simpson G, Jones K. How important is resilience among family members supporting relatives with traumatic brain injury or spinal cord injury? Clin Rehabil. 2013;27:367-77. 